\title{
Guideline
}

\section{Update of Guidelines for Laboratory Diagnosis of COVID-19 in Korea}

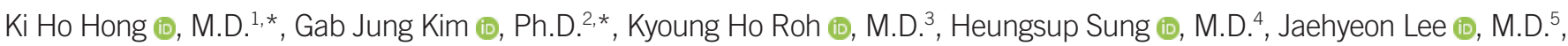

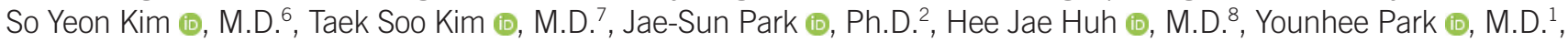

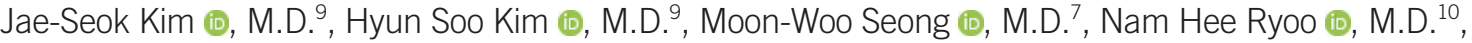

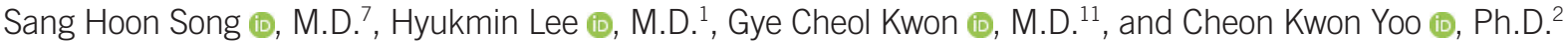

On behalf of

The COVID-19 Task Force, the Korean Society for Laboratory Medicine and the Bureau of Infectious Disease Diagnosis Control, the Korea Disease Control and Prevention Agency

${ }^{1}$ Department of Laboratory Medicine, Yonsei University College of Medicine, Seoul, Korea; ${ }^{2}$ Bureau of Infectious Disease Diagnosis Control, the Korea Disease Control and Prevention Agency, Osong, Korea; ${ }^{3}$ Department of Laboratory Medicine, National Health Insurance Service Ilsan Hospital, Goyang, Korea; ${ }^{4}$ Department of Laboratory Medicine, Asan Medical Center, University of Ulsan College of Medicine, Seoul, Korea; ${ }^{5}$ Department of Laboratory Medicine, Jeonbuk National University Medical School and Hospital, Jeonju, Korea; 'Department of Laboratory Medicine, National Medical Center, Seoul, Korea; ${ }^{7}$ Department of Laboratory Medicine, Seoul National University Hospital, Seoul, Korea; ${ }^{8}$ Department of Laboratory Medicine and Genetics, Samsung Medical Center, Sungkyunkwan University School of Medicine, Seoul, Korea; ${ }^{9}$ Department of Laboratory Medicine, Hallym University College of Medicine,

Chuncheon, Korea; ${ }^{10}$ Department of Laboratory Medicine, Keimyung University School of Medicine, Daegu, Korea; ${ }^{11}$ Department of Laboratory Medicine, College of Medicine, Chungnam National University, Daejeon, Korea

Korean Society for Laboratory Medicine and the Korea Disease Prevention and Control Agency have announced guidelines for diagnosing coronavirus disease (COVID-19) in clinical laboratories in Korea. With the ongoing pandemic, we propose an update of the previous guidelines based on new scientific data. This update includes recommendations for tests that were not included in the previous guidelines, including the rapid molecular test, antigen test, antibody test, and self-collected specimens, and a revision of the previous recommendations. This update will aid clinical laboratories in performing laboratory tests for diagnosing COVID-19.

Key Words: COVID-19, SARS-CoV-2, Laboratory diagnosis, Guidelines, Antigen, Antibody, Pooled test, Rapid molecular test, Saliva, Nasal swab
Received: January 20, 2022

Revision received: January 25, 2022

Accepted: February 7, 2022

Corresponding author: Hyukmin Lee, M.D. Department of Laboratory Medicine, Yonsei University College of Medicine, 50-1

Yonsei-ro, Seodaemun-gu, Seoul 03722, Korea

Tel: $+82-2-2228-2446$

Fax: +82-2-313-0956

E-mail: HMLEE71@yuhs.ac

\section{Co-corresponding author:}

Cheon Kwon Yoo, Ph.D.

Bureau of Infectious Disease Diagnosis

Control, Korea Disease Control and

Prevention Agency, Osong Health

Technology Administration Complex, 187 Osongsaengmyeong 2-ro, Osong-eup, Heungdeok-gu, Cheongju 28159, Korea

Tel: +82-43-719-8100

Fax: +82-43-719-8149

E-mail: ckyoo@korea.kr

*These authors equally contributed to this work.

\section{(c) (i) (\$)}

(c) Korean Society for Laboratory Medicine This is an Open Access article distributed under the terms of the Creative Commons Attribution Non-Commercial License (https://creativecommons.org/licenses/by-nc/4.0) which permits unrestricted non-commercial use, distribution, and reproduction in any medium, provided the original work is properly cited. 


\section{INTRODUCTION}

We propose an update of the Guidelines for Laboratory Diagnosis of Coronavirus Disease (COVID-19) in Korea issued by Korean Society for Laboratory Medicine (KSLM) and the Korea Disease Control and Prevention Agency (KDCA) that elaborate on the tests recommended for diagnosing COVID-19 [1]. This update includes recommendations for the rapid molecular test, antigen test, antibody test, and self-collected respiratory specimens, which were not covered in the previous guidelines, and a revision of the previous recommendations based on new scientific data (Table 1).

\section{MOLECULAR TESTS}

KSLM and KDCA recommend real-time reverse transcription (rRT)-PCR as a molecular test for diagnosing COVID-19. In addition to rRT-PCR, there are various isothermal amplification methods, including loop-mediated isothermal amplification and clustered regularly interspaced short palindromic repeats-based tests [2-7]. However, meta-analyses of these methods revealed insufficient performance or insufficient data; therefore, they should be used with caution in Korea at present [3-7].

\section{Specimen types}

Nasopharyngeal and oropharyngeal swabs collected simultaneously and placed in the same transport medium are no longer recommended for routine use because of the high risk of droplet generation in the process of placing two swabs in the same transport medium and because the viral loads are similar between the two specimen types; nasopharyngeal swabs are sufficient [8]. The use of an inactivating agent-containing transport medium (e.g., a chaotropic agent) for molecular tests provides safer specimen handling [9, 10].

\section{Self-collected respiratory specimens}

KSLM and KDCA generally do not recommend using self-collected respiratory specimens for diagnosing asymptomatic patients. Studies have investigated diagnosing COVID-19 using self-collected respiratory specimens, such as saliva, anterior nasal swabs (ANS), and mouthwash, as alternatives to nasopharyngeal and oropharyngeal swabs [11-14]. The advantage of these specimens is that they are easily obtained. However, recent prospective studies have revealed that the test sensitivities for saliva and ANS in asymptomatic patients were significantly lower than those for nasopharyngeal swabs [15-19]. In addition, pooled tests using saliva or ANS have lower sensitivities than individual tests using saliva or ANS [20-23]. Therefore, collecting such specimens can be considered for patients who need repeated specimen collection or in whom nasopharyngeal swabs are difficult to collect. However, the possibility of false negatives should be carefully considered in advance [24, 25]. The possibility of viral transmission during the process of self-collection should also be considered.

\section{Test interpretation}

KSLM and KDCA recommend using a molecular test that targets two or more sites of the severe acute respiratory syndrome coronavirus 2 (SARS-CoV-2) genome and to consider a COVID-19 diagnostic test positive only when all targets are positive. If the initial test result is inconclusive in a patient with no history of confirmed COVID-19, collecting a new specimen for retesting is recommended.

The following criteria apply only to the newly confirmed COVID-19 cases and in the course of treatment of a patient with confirmed COVID-19. The rRT-PCR test result can be judged

Table 1. Types of COVID-19 laboratory tests in Korea

\begin{tabular}{|c|c|c|}
\hline Type of test & Intended use & Caution \\
\hline rRT-PCR & $\begin{array}{l}\text { Confirmatory diagnosis in acute symptomatic patients } \\
\text { or screening of asymptomatic individuals }\end{array}$ & $\begin{array}{l}\text { Not suitable for quantitative interpretation. } \\
\text { Infectivity cannot be determined on the basis of PCR results alone. }\end{array}$ \\
\hline Pooled test using rRT-PCR & Screening of asymptomatic individuals & $\begin{array}{l}\text { Sensitivity may vary with the transport medium, nucleic acid extraction method, } \\
\text { and PCR reagent used, and the pool size. }\end{array}$ \\
\hline Rapid molecular test & Rapid screening under emergency situations & Positive results are recommended to be confirmed with a validated rRT-PCR. \\
\hline Antigen test & $\begin{array}{l}\text { Diagnosis for symptomatic patients within seven days } \\
\text { from symptom onset }\end{array}$ & $\begin{array}{l}\text { The false-negative rate is high in pre-symptomatic or asymptomatic patients. } \\
\text { The false-positive rate is high when prevalence is low. }\end{array}$ \\
\hline Antibody test & $\begin{array}{l}\text { Confirmation of past infection or multisystem } \\
\text { inflammation syndrome or serosurveillance }\end{array}$ & $\begin{array}{l}\text { Assays with high specificity should be used. } \\
\text { Not recommended for evaluating the risk of infection. }\end{array}$ \\
\hline
\end{tabular}

Abbreviation: rRT-PCR, real-time reverse transcription PCR. 
positive even if the fluorescent signal reaches the threshold after the cut-off cycle because of a decrease in the viral load.

- All genes positive: COVID-19-positive (SARS-CoV-2 detected)

- All genes negative: COVID-19-negative (SARS-CoV-2 not detected)

- Some genes positive as compared to the reference values: inconclusive

\section{Considerations for test interpretation}

Molecular tests that target a single site are not recommended for diagnosing COVID-19 as various mutations affecting test sensitivity have been reported [26-35]. Multiple targets can also discriminate non-specific reactions, background fluorescence signals, and cross-reactivity, which can cause false-positive results [36-38]. The targets do not necessarily have to be located in different genes. Some reagents target multiple sites but employ the same fluorescent dyes; in such cases, the manufacturer has to establish a method to differentiate between non-specific reaction and SARS-CoV-2 genome amplification for the user.

\section{Solutions for inconclusive results}

If the results are inconsistent after retesting, they can be judged false positive, and when the results are consistent, the results can be judged positive. If there is a possibility of cross-contamination, re-amplification of the extracted nucleic acids is not sufficient; the specimen must be re-extracted or a new specimen must be collected.

The possibility of COVID-19 can be judged by reviewing the patient's medical history. In some cases, an antibody test may help in interpreting inconsistent or inconclusive results. To determine the risk of cross-contamination, it is recommended to follow-up the laboratory's positive-test rate or to consider the location of other SARS-CoV-2-positive specimens on the PCR plate [39].

\section{Result reporting}

KSLM and KDCA do not recommend routine reporting of threshold cycle (Ct) values [40-43]. All currently approved COVID-19 molecular tests are qualitative tests. Respiratory specimens are not homogeneous in quality and the amount collected, and there are differences between reagents used, leading to large fluctuations in $\mathrm{Ct}$ values. In external quality programs of COVID-19 molecular tests conducted in Korea and other countries, a very wide range of $\mathrm{Ct}$ values (10-27) has been observed [44-47]. Making clinical judgments, e.g., on quarantine release, based on $\mathrm{Ct}$ values has a high probability of error [42, 43, 48, 49]. Ct values should be interpreted cautiously in consultation with the laboratory director.

\section{Pooled test using rRT-PCR}

KSLM and KDCA recommend that test performance must be verified before using in the pooled specimen test method for the screening of asymptomatic patients [40, 50]. The pooled rRTPCR test for COVID-19 uses pooled upper respiratory tract specimens for the screening of asymptomatic patients with COVID-19 [50-52]. If the pooled test result is positive, all specimens included in the pooled test are subjected to rRT-PCR individually for confirmation. This method cannot be used for confirming suspected COVID-19 and should be limited to the screening of asymptomatic patients. For suspected patients, rRT-PCR of individual specimens is recommended.

As the pooled specimen test method is a screening test, sensitivity should be maintained as high as possible; the possibility of a decrease in sensitivity should be considered [52, 53]. Sensitivity may vary with the transport medium, nucleic acid extraction method, and PCR reagent used and the pool size [54, 55]. Therefore, it is necessary to verify whether the pooled specimen test method can be applied to the conditions used in each laboratory before testing.

- For general matters and considerations, refer to the previous guidelines and the protocol of KSLM for the pooled specimen test method [50].

- Regarding the determination of the pool size, various factors should be considered, including the virus amount of the newly diagnosed patient, the nucleic acid extraction method used, and the performance of the PCR reagent. Generally, a pool of no more than five to six specimens is recommended.

- Before starting a new test or changing the test method, a combination of the nucleic acid extraction method and PCR reagent should be tested with sufficient positive specimens to confirm that $100 \%$ sensitivity is obtained for the pooled test. In the verification process, sufficient specimens with high Ct values (e.g., at least 30\% specimens with a Ct value $\geq 30$ ) should be used. These recommendations are based on the distribution of the $\mathrm{Ct}$ values of newly diagnosed cases in Korea $[50,56]$.

\section{RAPID MOLECULAR TEST}

KSLM and KDCA recommend using reagents and equipment with verified performance when using a rapid molecular test [57]. The rapid molecular test for COVID-19 is used for the confirmation of a COVID-19 diagnosis within a short time [58]. The test principle is the same as that of other molecular tests, but the use of optimal reagents and equipment saves time; results can 
generally be obtained within one hour. Rapid molecular tests can provide accurate results under emergency situations. To this end, the entire process from specimen input to obtaining test results must be automated.

Considering the performance of the currently available rapid molecular tests and the prevalence of COVID-19 in Korea, a rapid molecular test should be used only for screening, and positive specimens should be confirmed using a validated rRT-PCR test. A rapid molecular test is not recommended for the pooled specimen method, which requires maximum sensitivity. Rapid molecular tests that employ a general thermocycler and rRT-PCR reagent with a short reaction time are not suitable for emergency situations as not all processes are automated and the equipment is not suitable for detecting short-time reactions.

\section{Test procedure}

As most rapid molecular tests do not use positive and negative controls, an internal control must be included in the same reaction well as the specimen.

Before using the rapid molecular test, it is recommended to verify its performance with sufficient positive specimens to confirm that $100 \%$ sensitivity is obtained for multiple pooled specimens. In the verification process, it is recommended to include sufficient specimens with high Ct values (e.g., at least $30 \%$ of specimens with a $\mathrm{Ct}$ value $\geq 30$ ). These recommendations are based on the distribution of $\mathrm{Ct}$ values of newly reported cases in Korea $[50,56]$.

\section{Interpretation}

Even if only one of the target genes is present, it is considered presumptive positive, and a validated rRT-PCR test is recommended for confirmation. As rapid molecular tests are for screening, inconclusive results should be considered presumptive positive. The positive predictive value may be low when the prevalence is low as the specificity of the rapid molecular test is not sufficiently high. In such a case, both positive and inconclusive rapid molecular test results should be considered only as screening test results and the results should be confirmed using a conventional rRT-PCR test.

\section{ANTIGEN TEST}

KSLM and KDCA do not recommend using a SARS-CoV-2 antigen test for asymptomatic individuals. Considering the low sensitivity and specificity of the antigen tests and the relatively low prevalence of COVID-19 in Korea, SARS-CoV-2 antigen tests have a very limited role in the screening of asymptomatic patients in Korea [56, 59-63]. The European Centers for Disease Control and Prevention recommend that antigen tests should not be used for the screening of asymptomatic patients if the prevalence is $<10 \%$ [60]. The sensitivity of antigen tests using self-collected specimens, such as saliva or ANS, is even lower [63-67].

The use of a SARS-CoV-2 antigen test may be considered for symptomatic patients within seven days from symptom onset (1) when the prevalence and positive predictive value are high, (2) when the molecular test results are delayed for more than 48 hrs, and (3) when effective prophylactic treatment can be administered on the basis of clinical suspicion even after suspected false-negative results with the antigen test. A molecular test is recommended simultaneously with the antigen test to reduce the possibility of false positives or false negatives [68]. The manufacturer's instructions for immunochromatography must be followed strictly as result interpretation may be subjective [69].

\section{ANTIBODY TEST}

KSLM and KDCA do not recommend using an antibody test for diagnosing acute COVID-19 or for evaluating the risk of infection for individuals who have recovered from COVID-19 or who have been vaccinated for COVID-19 [40, 70-73]. SARS-CoV-2 antibody tests are indicated (1) for serosurveillance studies, (2) in the case of strong suspicion of past SARS-CoV-2 infection based on epidemiological and clinical results and repeated negative or indeterminate molecular tests, (3) in the case of suspected COVID-19-related multisystem inflammatory syndrome, (4) for the selection of convalescent plasma donors from patients who have recovered from COVID-19 for therapeutic purposes, (5) for studies aimed at investigating the efficacy or effectiveness of a vaccine, and (6) for entry into a country where a SARS-CoV-2 antibody test result is a prerequisite [74]. An antibody test with very high specificity (e.g., $\geq 99.5 \%$ ) should be used [75-77]. To diagnose a breakthrough infection in a vaccinated patient, an antibody test detecting antigens not targeted by the vaccine received should be used.

\section{LABORATORY GUIDELINES FOR BIOSAFETY AND INFECTION CONTROL}

KSLM and KDCA recommend that only fully COVID-19-vaccinated healthcare personnel perform the tests [78-82]. 


\section{ACKNOWLEDGEMENTS}

None.

\section{AUTHOR CONTRIBUTIONS}

Hong $\mathrm{KH}$ and Kim GJ reviewed the literature on the currently used general recommendations and wrote the manuscript. Roh $\mathrm{KH}$ and Sung $\mathrm{H}$ contributed to general concepts and recommendations. Lee J and Kim SY contributed to recommendations for antigen tests, pooling tests, and rapid molecular tests. Kim TS and Kim J-S contributed to recommendations for biosafety. Park $\mathrm{Y}$ and Kim HS contributed to recommendations for antibody testing. Park J-S, Huh HJ, Seong M-W, and Ryoo N collated protocols and interpreted results and contributed to recommendations. Lee H, Song SH, Kwon GC, and Yoo CK organized the task force and contributed to the concept and design of the guidelines.

\section{CONFLICTS OF INTEREST}

None.

\section{RESEARCH FUNDING}

None declared.

\section{ORCID}

Ki Ho Hong

Gab Jung Kim

Kyoung Ho Roh

Heungsup Sung

Jaehyeon Lee

So Yeon Kim

Taek Soo Kim

Hee Jae Huh

Younhee Park

Jae-Sun Park

Jae-Seok Kim

Hyun Soo Kim

Moon-Woo Seong

Nam Hee Ryoo

Sang Hoon Song

Hyukmin Lee

Gye Cheol Kwon

Cheon Kwon Yoo

\section{REFERENCES}

1. Hong KH, Lee SW, Kim TS, Huh HJ, Lee J, Kim SY, et al. Guidelines for laboratory diagnosis of coronavirus disease 2019 (COVID-19) in Korea. Ann Lab Med 2020;40:351-60.

2. Kevadiya BD, Machhi J, Herskovitz J, Oleynikov MD, Blomberg WR, Bajwa N, et al. Diagnostics for SARS-CoV-2 infections. Nat Mater 2021; 20:593-605.

3. Au WY and Cheung PPH. Diagnostic performances of common nucleic acid tests for SARS-CoV-2 in hospitals and clinics: a systematic review and meta-analysis. Lancet Microbe 2021;2:e704-14.

4. Freije CA and Sabeti PC. Detect and destroy: CRISPR-based technologies for the response against viruses. Cell Host Microbe 2021;29:689703.

5. Subali $A D$ and Wiyono L. Reverse transcriptase loop mediated isothermal amplification (RT-LAMP) for COVID-19 diagnosis: a systematic review and meta-analysis. Pathog Glob Health 2021;115:281-91.

6. Subsoontorn P, Lohitnavy M, Kongkaew C. The diagnostic accuracy of isothermal nucleic acid point-of-care tests for human coronaviruses: a systematic review and meta-analysis. Sci Rep:2020;10:22349.

7. Thwe PM, Maiyo E, Ren P. Abbott ID now COVID-19 assay performance: a year in review. Diagn Microbiol Infect Dis 2021;101:115536.

8. Mohammadi A, Esmaeilzadeh E, Li Y, Bosch RJ, Li JZ. SARS-CoV-2 detection in different respiratory sites: a systematic review and meta-analysis. EBiomedicine 2020;59:102903.

9. Pastorino B, Touret F, Gilles M, Luciani L, de Lamballerie X, Charrel RN. Evaluation of chemical protocols for inactivating SARS-CoV-2 infectious samples. Viruses 2020;12:624.

10. Welch SR, Davies KA, Buczkowski H, Hettiarachchi N, Green N, Arnold $\mathrm{U}$, et al. Analysis of inactivation of SARS-CoV-2 by specimen transport media, nucleic acid extraction reagents, detergents, and fixatives. J Clin Microbiol 2020;58:e01713-20.

11. Harrison C, Lindholm DE, Steer AC, Osowicki J. A systematic review and meta-analysis of upper airway swab collection for detection of viral and bacterial pathogens by individuals or caregivers compared to health care workers. J Clin Microbiol 2021;59:e0230420.

12. Lee RA, Herigon JC, Benedetti A, Pollock NR, Denkinger CM. Performance of saliva, oropharyngeal swabs, and nasal swabs for SARS-CoV-2 molecular detection: a systematic review and meta-analysis. J Clin Microbiol 2021;59:e02881-20.

13. Butler-Laporte G, Lawandi A, Schiller I, Yao M, Dendukuri N, McDonald EG, et al. Comparison of saliva and nasopharyngeal swab nucleic acid amplification testing for detection of SARS-CoV-2: a systematic review and meta-analysis. JAMA Intern Med 2021;181:353-60.

14. Bastos ML, Perlman-Arrow S, Menzies D, Campbell JR. The sensitivity and costs of testing for SARS-CoV-2 infection with saliva versus nasopharyngeal swabs: a systematic review and meta-analysis. Ann Intern Med 2021;174:501-10.

15. Nacher M, Mergeay-Fabre M, Blanchet D, Benoit O, Pozl T, Mesphoule $\mathrm{P}$, et al. Prospective comparison of saliva and nasopharyngeal swab sampling for mass screening for COVID-19. Front Med (Lausanne) 2021;8: 621160.

16. Nagura-Ikeda M, Imai K, Tabata S, Miyoshi K, Murahara N, Mizuno T, et al. Clinical evaluation of self-collected saliva by quantitative reverse transcription-PCR (RT-qPCR), direct RT-qPCR, reverse transcriptionloop-mediated isothermal amplification, and a rapid antigen test to diagnose COVID-19. J Clin Microbiol 2020;58:e01438-20.

17. Marx GE, Biggerstaff BJ, Nawrocki CC, Totten SE, Travanty EA, Burakoff AW, et al. Detection of severe acute respiratory syndrome coronavirus 2 
on self-collected saliva or anterior nasal specimens compared with healthcare personnel-collected nasopharyngeal specimens. Clin Infect Dis 2021;73(S1):S65-73.

18. Smith-Jeffcoat SE, Koh M, Hoffman A, Rebolledo PA, Schechter MC, Miller HK, et al. Effects of patient characteristics on diagnostic performance of self-collected samples for SARS-CoV-2 testing. Emerg Infect Dis 2021;27:2081-9.

19. Congrave-Wilson Z, Lee Y, Jumarang J, Perez S, Bender JM, Bard JD, et al. Change in saliva RT-PCR sensitivity over the course of SARS-CoV-2 infection. JAMA 2021;326:1065-7.

20. Migueres M, Vellas C, Abravanel F, Da Silva I, Dimeglio C, Ferrer V, et al. Testing individual and pooled saliva samples for sars-cov-2 nucleic acid: a prospective study. Diagn Microbiol Infect Dis 2021;101:115478.

21. Barat B, Das S, De Giorgi V, Henderson DK, Kopka S, Lau AF, et al. Pooled saliva specimens for SARS-CoV-2 testing. J Clin Microbiol 2021;59:e0248620.

22. Ho YI, Wong AH, Tang KPS, Wong RCW, Leung ECM, Lai RWM. Comparison of three commercial SARS-CoV-2 assays for pooled testing of deep throat saliva for surveillance of patients attending general outpatient clinics. J Med Virol 2021;93:1917-9.

23. McMillen T, Jani K, Babady NE. Evaluation of sample pooling for SARSCoV-2 RNA detection in nasopharyngeal swabs and salivas on the Roche Cobas 6800. J Clin Virol 2021;138:104790.

24. Hanson KE, Caliendo AM, Arias CA, Englund JA, Lee MJ, Loeb M, et al. Infectious Diseases Society of America guidelines on the diagnosis of COVID-19. Clin Infect Dis 2021:ciaa67.

25. Hanson KE, Caliendo AM, Arias CA, Hayden MK, Englund JA, Lee MJ, et al. The Infectious Diseases Society of America guidelines on the diagnosis of COVID-19: molecular diagnostic testing. Clin Infect Dis 2021: ciab048.

26. US Food and Drug Administration. SARS-CoV-2 viral mutations: impact on COVID-19 tests. https://www.fda.gov/medical-devices/coronaviruscovid-19-and-medical-devices/sars-cov-2-viral-mutations-impact-covid19-tests (Updated on Dec 28, 2021).

27. Artesi M, Bontems S, Göbbels P, Franckh M, Maes P, Boreux R, et al. A recurrent mutation at position 26340 of SARS-CoV-2 is associated with failure of the $E$ gene quantitative reverse transcription-PCR utilized in a commercial dual-target diagnostic assay. J Clin Microbiol 2020;58:e0159820.

28. Ziegler K, Steininger P, Ziegler R, Steinmann J, Korn K, Ensser A. SARSCoV-2 samples may escape detection because of a single point mutation in the N gene. Euro Surveill 2020;25:2001650.

29. Hong KH, In JW, Lee J, Kim SY, Lee KA, Kim S, et al. Prevalence of a single-nucleotide variant of SARS-CoV-2 in Korea and its impact on the diagnostic sensitivity of the Xpert Xpress SARS-CoV-2 assay. Ann Lab Med 2022;42:96-9.

30. Vanaerschot M, Mann SA, Webber JT, Kamm J, Bell SM, Bell J, et al. Identification of a polymorphism in the $\mathrm{N}$ gene of SARS-CoV-2 that adversely impacts detection by reverse transcription-PCR. J Clin Microbiol 2020;59:e02369-20.

31. Rhoads DD, Plunkett D, Nakitandwe J, Dempsey A, Tu ZJ, Procop GW, et al. Endemic SARS-CoV-2 polymorphisms can cause a higher diagnostic target failure rate than estimated by aggregate global sequencing data. J Clin Microbiol 2021;59:e0091321.

32. Khoshchehreh M, Wald-Dickler N, Holtom P, Butler-Wu SM. A needle in the haystack? Assessing the significance of envelope (E) gene-negative, nucleocapsid (N2) gene-positive SARS-CoV-2 detection by the Cepheid Xpert Xpress SARS-COV-2 assay. J Clin Virol 2020;133:104683.

33. Tahan S, Parikh BA, Droit L, Wallace MA, Burnham CD, Wang D. SARSCoV-2 E gene variant alters analytical sensitivity characteristics of viral detection using a commercial reverse transcription-PCR assay. J Clin Microbiol 2021;59:e0007521.

34. Bal A, Destras G, Gaymard A, Stefic K, Marlet J, Eymieux S, et al. Twostep strategy for the identification of SARS-CoV-2 variant of concern 202012/01 and other variants with spike deletion H69-V70, France, August to December 2020. Euro Surveill 2021;26:2100008.

35. Borges V, Sousa C, Menezes L, Gonçalves AM, Picão M, Almeida JP, et al. Tracking SARS-CoV-2 lineage B.1.1.7 dissemination: insights from nationwide spike gene target failure (SGTF) and spike gene late detection (SGTL) data, Portugal, week 492020 to week 32021 . Euro Surveill 2021;26:2100131.

36. Huggett JF, Benes V, Bustin SA, Garson JA, Harris K, Kammel M, et al. Cautionary note on contamination of reagents used for molecular detection of SARS-CoV-2. Clin Chem 2020;66:1369-72.

37. Rosebrock AP. DNA cross-reactivity of the CDC-specified SARS-CoV-2 specimen control leads to potential for false negatives and underreporting of viral infection. Clin Chem 2021;67:435-7.

38. Braunstein GD, Schwartz L, Hymel P, Fielding J. False positive results with SARS-CoV-2 RT-PCR tests and how to evaluate a RT-PCR-positive test for the possibility of a false positive result. J Occup Environ Med 2021;63:e159-62.

39. Sung H, Roh KH, Hong KH, Seong MW, Ryoo N, Kim HS, et al. COVID-19 molecular testing in Korea: practical essentials and answers from experts based on experiences of emergency use authorization assays. Ann Lab Med 2020;40:439-47.

40. Zhang YV, Wiencek J, Meng QH, Theel ES, Babic N, Sepiashvili L, et al. AACC practical recommendations for implementing and interpreting SARS-CoV-2 EUA and LDT serologic testing in clinical laboratories. Clin Chem 2021;67:1188-200.

41. Infectious Disease Society of America and Association for Molecular Pathology. IDSA and AMP joint statement on the use of SARS-CoV-2 PCR cycle threshold (Ct) values for clinical decision-making 2021. https:// www.idsociety.org/globalassets/idsa/public-health/covid-19/idsa-ampstatement.pdf (Updated on Mar 2021)

42. American Association for Clinical Chemistry. AACC Recommendation for reporting SARS-CoV-2 cycle threshold (CT) values 2021. https:// www.aacc.org/science-and-research/covid-19-resources/statementson-covid-19-testing/aacc-recommendation-for-reporting-sars-cov-2-cycle-threshold-ct-values (Updated on Jul 2021)

43. Evans D, Cowen S, Kammel M, O'Sullivan DM, Stewart G, Grunert HP, et al. The dangers of using $\mathrm{Cq}$ to quantify nucleic acid in biological samples: a lesson from COVID-19. Clin Chem 2021;68:153-62.

44. Buchta C, Görzer I, Chiba P, Camp JV, Holzmann H, Puchhammer-Stöckl $\mathrm{E}$, et al. Variability of cycle threshold values in an external quality assessment scheme for detection of the SARS-CoV-2 virus genome by RTPCR. Clin Chem Lab Med 2021;59:987-94.

45. Fischer C, Mögling R, Melidou A, Kühne A, Oliveira-Filho EF, Wolff T, et al. Variable sensitivity of SARS-CoV-2 molecular detection in European expert laboratories: external quality assessment, June and July 2020. J Clin Microbiol 2021;59:e02676-20.

46. Sung H, Han MG, Yoo CK, Lee SW, Chung YS, Park JS, et al. Nationwide external quality assessment of SARS-CoV-2 molecular testing, South Korea. Emerg Infect Dis 2020;26:2353-60.

47. Matheeussen V, Corman VM, Donoso Mantke O, McCulloch E, Lammens $\mathrm{C}$, Goossens $\mathrm{H}$, et al. International external quality assessment for SARS-CoV-2 molecular detection and survey on clinical laboratory preparedness during the COVID-19 pandemic, April/May 2020. Euro Surveill 2020;25:2001223.

48. Binnicker MJ. Challenges and controversies to testing for COVID-19. J Clin Microbiol 2020;58:e01695-20. 
49. Binnicker MJ. Can testing predict SARS-CoV-2 infectivity? The potential for certain methods to be surrogates for replication-competent virus. J Clin Microbiol 2021;59:e0046921.

50. Kim SY, Lee J, Sung H, Lee H, Han MG, Yoo CK, et al. Pooling upper respiratory specimens for rapid mass screening of COVID-19 by realtime RT-PCR. Emerg Infect Dis 2020;26:2469-72.

51. Yelin I, Aharony N, Tamar ES, Argoetti A, Messer E, Berenbaum D, et al. Evaluation of COVID-19 RT-qPCR test in multi sample pools. Clin Infect Dis 2020;71:2073-8.

52. Lippi G. Upper respiratory samples pooling for screening SARS-CoV-2 infection: ready for the prime time? Clin Chem Lab Med 2020;58:e307-9.

53. Lee J, Kim SY, Sung H, Lee SW, Lee H, Roh KH, et al. Challenges and issues of SARS-CoV-2 pool testing. Lancet Infect Dis 2020;20:1232-3.

54. Wang H, Hogan CA, Miller JA, Sahoo MK, Huang C, Mfuh KO, et al. Performance of nucleic acid amplification tests for detection of severe acute respiratory syndrome coronavirus 2 in prospectively pooled specimens. Emerg Infect Dis 2021;27:92-103.

55. Garg A, Ghoshal U, Patel SS, Singh DV, Arya AK, Vasanth S, et al. Evaluation of seven commercial RT-PCR kits for COVID-19 testing in pooled clinical specimens. J Med Virol 2021;93:2281-6.

56. Lee J, Kim SY, Huh HJ, Kim N, Sung H, Lee H, et al. Clinical performance of the Standard Q COVID-19 Rapid Antigen Test and simulation of its real-world application in Korea. Ann Lab Med 2021;41:588-92.

57. Bohn MK, Mancini N, Loh TP, Wang CB, Grimmler M, Gramegna M, et al. IFCC interim guidelines on molecular testing of SARS-CoV-2 infection. Clin Chem Lab Med 2020;58:1993-2000.

58. Dinnes J, Deeks JJ, Berhane S, Taylor M, Adriano A, Davenport C, et al. Rapid, point-of-care antigen and molecular-based tests for diagnosis of SARS-CoV-2 infection. Cochrane Database Syst Rev 2021;3:CD013705.

59. Hanson KE, Altayar O, Caliendo AM, Arias CA, Englund JA, Hayden MK, et al. The Infectious Diseases Society of America guidelines on the diagnosis of COVID-19: antigen testing. Clin Infect Dis 2021:ciab557.

60. European Centre for Disease Control and Prevention. Options for the Use of Rapid Antigen Tests for COVID-19 in the EU/EEA and the UKfirst update. https://www.ecdc.europa.eu/en/publications-data/optionsuse-rapid-antigen-tests-covid-19-eueea-first-update (Updated on Oct 2021).

61. Pray IW, Ford L, Cole D, Lee C, Bigouette JP, Abedi GR, et al. Performance of an antigen-based test for asymptomatic and symptomatic SARS-CoV-2 testing at two university campuses-Wisconsin, September-October 2020. MMWR Morb Mortal Wkly Rep 2021;69:1642-7.

62. Oh SM, Jeong H, Chang E, Choe PG, Kang CK, Park WB, et al. Clinical application of the Standard Q COVID-19 Ag Test for the detection of SARSCoV-2 infection. J Korean Med Sci 2021;36:e101.

63. Brihn A, Chang J, OYoung K, Balter S, Terashita D, Rubin Z, et al. Diagnostic performance of an antigen test with RT-PCR for the detection of SARS-CoV-2 in a hospital setting — Los Angeles County, California, JuneAugust 2020. MMWR Morb Mortal Wkly Rep 2021;70:702-6.

64. Ferguson J, Dunn S, Best A, Mirza J, Percival B, Mayhew M, et al. Validation testing to determine the sensitivity of lateral flow testing for asymptomatic SARS-CoV-2 detection in low prevalence settings: testing frequency and public health messaging is key. PLoS Biol 2021;19:e3001216.

65. Tinker SC, Szablewski CM, Litvintseva AP, Drenzek C, Voccio GE, Hunter MA, et al. Point-of-care antigen test for SARS-CoV-2 in asymptomatic college students. Emerg Infect Dis 2021;27:2662-5.

66. García-Fiñana M, Hughes DM, Cheyne CP, Burnside G, Stockbridge M, Fowler TA, et al. Performance of the Innova SARS-CoV-2 antigen rapid lateral flow test in the Liverpool asymptomatic testing pilot: population based cohort study. BMJ 2021;374:n1637.

67. Ford L, Lee C, Pray IW, Cole D, Bigouette JP, Abedi GR, et al. Epidemio- logic characteristics associated with severe acute respiratory syndrome coronavirus 2 (SARS-CoV-2) antigen-based test results, real-time reverse transcription polymerase chain reaction (rRT-PCR) cycle threshold values, subgenomic RNA, and viral culture Results from university testing. Clin Infect Dis 2021;73:e1348-55.

68. Blairon L, Wilmet A, Beukinga I, Tré-Hardy M. Implementation of rapid SARS-CoV-2 antigenic testing in a laboratory without access to molecular methods: experiences of a general hospital. J Clin Virol 2020;129: 104472.

69. Whitman JD, Hiatt J, Mowery CT, Shy BR, Yu R, Yamamoto TN, et al. Evaluation of SARS-CoV-2 serology assays reveals a range of test performance. Nat Biotechnol 2020;38:1174-83.

70. Ong DSY, Fragkou PC, Schweitzer VA, Chemaly RF, Moschopoulos CD, Skevaki C; European Society of Clinical Microbiology and Infectious Diseases (ESCMID) Study Group for Respiratory Viruses (ESGREV). How to interpret and use COVID-19 serology and immunology tests. Clin Microbiol Infect 2021;27:981-6.

71. Theel ES, Slev P, Wheeler S, Couturier MR, Wong SJ, Kadkhoda K. The role of antibody testing for SARS-CoV-2: is there one? J Clin Microbiol 2020;58:e00797-20.

72. US Food and Drug Administration. Antibody testing is not currently recommended to assess immunity after COVID-19 vaccination: FDA safety communication. https://www.fda.gov/medical-devices/safety-communications/antibody-testing-not-currently-recommended-assess-immunityafter-covid-19-vaccination-fda-safety (Updated on May 2021).

73. Centers for Disease Control and Prevention. Interim guidelines for COVID-19 antibody testing. https://www.cdc.gov/coronavirus/2019-ncov/lab/ resources/antibody-tests-guidelines.html (Updated on Jan 2022)

74. Embassy of the People's Republic of China in the United States of America. Notice on airline boarding requirements for certificates of negative nucleic acid and anti-body blood tests results. http://www.china-embassy.org/eng/notices/t1828184.htm (Updated on Oct 2020).

75. Hanson KE, Caliendo AM, Arias CA, Englund JA, Hayden MK, Lee MJ, et al. Infectious Diseases Society of America guidelines on the diagnosis of COVID-19: serologic testing. Clin Infect Dis 2020:ciaa1343.

76. Park Y, Hong KH, Lee SK, Hyun J, Oh EJ, Lee J, et al. Performance Comparison of Five SARS-CoV-2 Antibody Assays for Seroprevalence Studies. Ann Lab Med 2022;42:71-8.

77. Yun S, Ryu JH, Jang JH, Bae H, Yoo SH, Choi AR, et al. Comparison of SARS-CoV-2 Antibody Responses and Seroconversion in COVID-19 Patients Using Twelve Commercial Immunoassays. Ann Lab Med 2021; 41:577-87.

78. Centers for Disease Control and Prevention. Interim laboratory biosafety guidelines for handling and processing specimens associated with coronavirus disease 2019 (COVID-19). https://www.cdc.gov/coronavirus/ 2019-ncov/lab/lab-biosafety-guidelines.html (Updated on Dec 2021)

79. World Health Organization. Laboratory biosafety guidance related to coronavirus disease (COVID-19): interim guidance, 28 January 2021. https://www.who.int/publications/i/item/WHO-WPE-GIH-2021.1. (Updated on Jan 2021)

80. Kaufer AM, Theis T, Lau KA, Gray JL, Rawlinson WD. Laboratory biosafety measures involving SARS-CoV-2 and the classification as a Risk Group 3 biological agent. Pathology 2020;52:790-5.

81. Bloise I, Gómez-Arroyo B, García-Rodríguez J; SARS-CoV-2 Working Group. Detection of SARS-CoV-2 on high-touch surfaces in a clinical microbiology laboratory. J Hosp Infect 2020;105:784-6.

82. Zuckerman NS, Pando R, Bucris E, Drori Y, Lustig Y, Erster O, et al. Comprehensive analyses of SARS-CoV-2 transmission in a public health virology laboratory. Viruses 2020;12:854. 